\title{
DIGESTIBILIDADE DA FRAÇÃO NITROGENADA EM BOVINOS ALIMENTADOS COM RAÇÕES CONTENDO DIFERENTES FONTES DE NITROGENIO
}

\section{(Digestibility of nitrogen fraction in bovines feed with nitrogen from different ration sources)}

\author{
ROSSI JUNIOR, P. ${ }^{1}$; SAMPAIO, A.A.M. ${ }^{2}$; VIEIRA, P.F. ${ }^{3}$
}

\author{
'Departamento de Zootecnia da UFPR/SCA; \\ ${ }^{2}$ Departamento de Zootecnia da FCAV/UNESP; \\ ${ }^{3}$ Departamento de Zootecnia da FCAV/UNESP.
}

\begin{abstract}
RESUMO - O objetivo do presente trabalho foi estudar a digestibilidade da fração nitrogenada em animais alimentados com diferentes fontes de nitrogênio $(N)$. As dietas foram fornecidas a bezerros da raça Holandesa, canulados no abomaso, com idade aproximada de 8 meses e peso médio de $187 \mathrm{~kg}$, totalizando 21 animais escolhidos aleatoriamente, formando o grupo de repetições experimentais. As rações experimentais foram constituídas de $40 \%$ de volumoso (feno de Capim-de-Rhodes) e $60 \%$ de concentrado (milho, farelo de algodão, levedura, uréia, melaço e minerais), sendo: $R_{A}$ : ração com farelo de algodão; $R_{L}$ : ração com levedura; $R_{u}$ : ração com uréia. A quantidade de $\mathrm{N}$ ingerido em $\mathrm{g} / \mathrm{dia}$ e em relação ao peso metabólico não apresentou diferenças significativas $(P>0,05)$ à medida que se variou a fonte nitrogenada das dietas. $\mathrm{O} N$ presente no abomaso $(\mathrm{g} /$ dia) também não apresentou diferenças significativas entre as dietas $(P>0,05)$. A digestibilidade aparente do $\mathrm{N}$ foi superior $(\mathrm{P}<0,05)$ na dieta $R U(53,61 \%)$ em relação às dietas RA e RL (46,66 e 46,37\%, respectivamente). As dietas $R A$ e $R L$, apesar de apresentarem maiores quantidades de nitrogênio nãoamoniacol (NNA) presentes no abomaso $(71,75$ e 72,38 $\mathrm{g} /$ dia respectivamente) em relação à dieta $R U(P<0,05)$, também foram as que apresentaram maiores quantidades eliminadas nas fezes (37,74 e 41,20 g/dia, respectivamente); isto contribuiu para que a quantidade de NNA absorvida no intestino ( $\mathrm{g} / \mathrm{dia}$ ) não apresentasse diferenças significativas entre as dietas $(P>0,05)$. As fontes nitrogenadas das dietas interferiram sobre a digestibilidade aparente do nitrogênio.
\end{abstract}

Palavras-chave: farelo de algodão, fontes nitrogenadas, fração nitrogenada, levedura, uréia.

ABSTRACT - The present research work has been carried out with the aim to study the digestibility of nitrogen fractions, in animals fed with different nitrogen sources rations. The diets were supplied to Holstein steers with abomasal cannulas, with eight months of age and average weight of $187 \mathrm{~kg}$, in a total of 21 animals selected at random. The experimental rations were constituted by $40 \%$ roughage (Rhodes grass hay) and
$60 \%$ concentrate (corn, cotton seed meal, yeast, urea, molasses and minerals) by concentrate mixture. The utilized treatments were: RA (ration with cotton seed meal); RL (ration with yeast); RU (ration with urea). The amount of nitrogen $(\mathrm{N})$ intaked in grams per day ( $\mathrm{g} /$ day) in relation of metabolic weight $\left(\mathrm{g} / \mathrm{kgLW}^{0.75}\right)$ did not display significant differences $(P>0.05)$ with the change of nitrogen source of diets. Also the $\mathrm{N}$ present in abomasum (g/day) did not display significant differences $(P>0.05)$. The $N$ apparent digestibility was superior $(P<0.05)$ in $\mathrm{RU}$ diet (53.61\%) when compared to RA and $R L$ diets (46.66 and $46.37 \%$, respectively). $R A$ and $R L$ diets, despite presenting the largest amount of NNA in the abomasum (71.75 and $72.38 \mathrm{~g} /$ day respectively) in relation to $R U$ diet $(P<0.05)$, were the ones that present the largest amounts eliminated in feaces as well (37.74 and $41.20 \mathrm{~g} /$ day, respectively). This fact contributed for the amounts absorbed of NNA by the intestine ( $\mathrm{g} /$ day), which did not present significant differences between the diets $(P>0.05)$. The protein sources of diets intervened on the nitrogen apparent digestibility.

Key-words: cotton seed meal, nitrogen fraction, nitrogen sources, urea, yeast.

\section{Introdução}

Fontes de proteína de baixa degradabilidade no rúmen aumentam o crescimento de bovinos jovens e ovinos (HUBER, 1981, citado por KING et al., 1990) além de aumentar a produção de leite de vacas (KUNG e HUBER, 1983, citados por KING et al., 1990), porém uma quantidade de proteína degradada no rúmen é necessária para manter a atividade ruminal.

A combinação de fontes de proteína degradável e não degradável no rúmen possibilitam aumento do fluxo de proteína da dieta e de proteína microbiana para o intestino e conseqüentemente, geram um aumento na produtividade de bovinos jovens. Isto foi observado no estudo realizado por COOMER et al. (1993), onde os autores variaram a fonte nitrogenada da dieta (farelo de soja e glutenose de milho) e observaram diferenças no fluxo de aminoácidos para o abomaso, causado principalmente pelo aumento do fluxo de aminoácidos 
oriundos da proteína microbiana, apesar de não se ter observado diferenças na composição em aminoácidos das bactérias. Os autores concluíram que a suplementação de bovinos jovens com proteína não degradável pode aumentar o fluxo de proteína e aminoácidos para o intestino aumentado o suprimento de proteína metabolizável para o animal, reforçando o que foi apresentado por ORSKOV (1977), citado por COOMER et al. (1993).

Porém, o fornecimento de fontes nitrogenadas ricas em proteína não degradável no rúmen visando aumentar o suprimento de proteína dietética para o intestino delgado tem levado a resultados de desempenhos animais não satisfatórios, atribuídos, dentre outros fatores, à redução na síntese microbiana, baixa disponibilidade intestinal ou limitação na composição de aminoácidos da fonte nitrogenada (CLARK et al., 1992).

Desta forma, o presente trabalho teve como objetivo estudar a digestibilidade da fração nitrogenada em animais alimentados com rações contendo diferentes fontes de nitrogênio.

\section{Material e Métodos}

Foram utilizados 21 bezerros da raça Holandesa, com idade aproximada de 8 meses e peso vivo médio no início do período experimental de $187 \mathrm{~kg}$, sendo escolhidos aleatoriamente 7 animais para constituir as repetições experimentais (7 por tratamento).

As rações experimentais foram constituídas de 40 $\%$ de volumoso e $60 \%$ de concentrado. Como volumoso foi utilizado o feno de capim-de-Rhodes e para o concentrado foi utilizado milho, farelo de algodão, levedura, uréia, melaço e minerais. Estes ingredientes constituíram as rações cuja variação foi a fonte nitrogenada sendo: $R_{A}$ : ração com farelo de algodão; $R_{L}$ : ração com levedura; $R_{U}$ : ração com uréia.

As rações foram balanceadas segundo o NRC (1989) para atender as exigências de 1,5 vezes à mantença dos animais. Pesados os animais no final do período experimental não foi observado ganho em peso vivo em relação à média inicial reportada anteriormente (187 $\mathrm{kg}$ peso vivo médio inicial)

As quantidades de ração fornecidas aos animais durante os períodos de colheita foram padronizadas com base no consumo voluntário, sendo esta padronização obtida a partir dos dados relativos ao animal que apresentou a menor ingestão de matéria seca por unidade de tamanho metabólico, fato que pode explicar o baixo desempenho observado.

Nas dietas, digesta abomasal e fezes foram determinados: matéria seca (MS), extrato etéreo (EE), cinzas (Cz), nitrogênio total (NT) e N amoniacal, segundo os métodos da A.O.A.C. (1970).

A proporção dos ingredientes nas dietas, a composição bromatológica e o consumo diário, são apresentados nas TABELAS 1, 2 e 3, respectivamente.

TABELA 1 - COMPOSIÇÃO DAS RAÇÕES EXPERIMENTAIS (\% MS).

\begin{tabular}{lccc}
\hline & \multicolumn{3}{c}{ Rações Experimentais } \\
\cline { 2 - 4 } Ingredientes & $\mathrm{RU}$ & $\mathrm{RA}$ & $\mathrm{RL}$ \\
\hline Feno de Capim-de-Rhodes & 40,00 & 40,00 & 40,00 \\
Fubá de milho & 52,35 & 30,00 & 31,49 \\
Farelo de algodão & - & 24,00 & - \\
Levedura & - & - & 22,51 \\
Uréia & 1,65 & - & - \\
Melaço & 4,50 & 4,50 & 4,50 \\
Mistura mineral & 1,50 & 1,50 & 1,50 \\
\hline
\end{tabular}

$R U=$ ração com uréia; $R A=$ ração com farelo de algodão; $R L=$ ração com levedura.

TABELA 2 - COMPOSIÇÃO QUÍMICA DAS RAÇÕES EXPERIMENTAIS.

\begin{tabular}{lccc} 
& \multicolumn{3}{c}{ Rações experimentais } \\
\cline { 2 - 4 } & $\mathrm{RU}$ & $\mathrm{RA}$ & $\mathrm{RL}$ \\
\hline Matéria Seca (\%) & 88,87 & 88,88 & 89,44 \\
Nitrogênio Total (\%MS) & 2,12 & 2,18 & 2,23 \\
Extrato Etéreo (\% MS) & 3,92 & 3,84 & 3,22 \\
Cinza (\% MS) & 4,78 & 5,61 & 5,92 \\
Matéria Orgânica (\% MS) & 95,22 & 94,40 & 94,08 \\
Carboidratos Totais (\% MS) & 78,07 & 76,90 & 76,94 \\
\hline
\end{tabular}

$\mathrm{RU}=$ ração com uréia; $\mathrm{RA}=$ ração com farelo de algodão; $\mathrm{RL}=$ ração com levedura. 
Digestibilidade da fração nitrogenada em bovinos alimentados com rações contendo diferentes fontes de nitrogênio

TABELA 3 - CONSUMO MÉDIO DIÁRIO DE MATÉRIA SECA (MS) DAS RAÇÕES EXPERIMENTAIS.

\begin{tabular}{lccc}
\hline & \multicolumn{3}{c}{ Tratamentos } \\
\cline { 2 - 4 } & $\mathrm{RU}$ & $\mathrm{RA}$ & $\mathrm{RL}$ \\
\hline $\mathrm{kg} / \mathrm{dia}$ & 4,54 & 4,44 & 4,53 \\
$\% \mathrm{PV}$ & 2,42 & 2,42 & 2,42 \\
$\mathrm{~g} / \mathrm{kgPV} 0,75$ & 89,42 & 88,66 & 89,13 \\
\hline
\end{tabular}

$\mathrm{RU}=$ ração com uréia; $\mathrm{RA}=$ ração com farelo de algodão; $\mathrm{RL}=$ ração com levedura; $\mathrm{PV}=$ peso vino.

Os primeiros dez dias foram de adaptação dos animais às rações experimentais e a partir do 11 - dia foi fornecido alimento na quantidade padronizada.

Após o período de adaptação iniciou-se o período de colheita de digesta do abomaso por 7 dias. A amostragem de digesta do abomaso foi feita retirandose a tampa da cânula a cada 28 horas de intervalo e coletando-se um volume aproximado de $400 \mathrm{ml}$ de cada um dos animais. A seguir o conteúdo foi guardado em frascos plásticos, previamente identificados, sob congelamento $\left(-15^{\circ} \mathrm{C}\right)$, para posterior determinação de sua composição.

A colheita de fezes também foi feita durante 7 dias, sendo a amostragem feita duas vezes por dia (7 e $16 \mathrm{~h}$ ), retirando-se das caixas coletoras das gaiolas, em torno de $2 \%$ de cada porção excretada, após a pesagem e homogeneização. As amostras diárias de fezes foram reunidas, formando uma amostra composta para cada animal, ração e período, sendo estocadas a $-15^{\circ} \mathrm{C}$.

Anteriormente ao fornecimento das rações experimentais foi fornecido a cada animal $5,0 \mathrm{~g}$ de óxido crômico $\left(\mathrm{Cr}_{2} \mathrm{O}_{3}\right)$ na forma de cápsulas de papel. A concentração de cromo no conteúdo abomasal foi determinada nas amostras colhidas nos intervalos descritos anteriormente. O óxido crômico na digesta abomasal foi determinado por espectofotometria de absorção atômica, segunda a técnica descrita por WILLIAMS et al. (1962).

Para a análise dos dados foi utilizado o delineamento inteiramente casualizado com três tratamentos e sete repetições, conforme o modelo (STEEL e TORRIE, 1981): $Y_{i j}=H+F_{i}+\epsilon_{i j}$, onde: $Y_{i j}=$ valor observado, $H=$ média geral, $F_{i}=$ efeito das fontes nitrogenadas $(i=1$, 2, 3) $\mathrm{e} \epsilon_{\mathrm{ij}}=$ efeito dos fatores não controlados na parcela i, na repetição $j(1,2, \ldots, 7)$.

\section{Resultados e Discussão}

$\mathrm{Na}$ TABELA 4 podem ser observados os dados de consumo e das quantidades médias diárias de nitrogênio (N) presente no abomaso e nas fezes, assim como as digestibilidades aparentes totais, no rúmen e no intestino.

A quantidade de $\mathrm{N}$ ingerido em gramas por dia $(\mathrm{g} /$ dia) e em relação ao peso metabólico $\left(\mathrm{g} / \mathrm{kgPV}^{0,75}\right)$ não apresentou diferenças significativas $(P>0,05)$ à medida que se variou a fonte nitrogenada das dietas. $\mathrm{O} N$ presente no abomaso ( $\mathrm{g} / \mathrm{dia}$ ) também não apresentou diferenças significativas entre as dietas $(P>0,05)$.

TABELA 4 - CONSUMO E QUANTIDADES MÉDIAS DIÁRIAS DE NITROGÊNIO (N), PRESENTE NO ABOMASO E NAS FEZES E DIGESTIBILIDADES APARENTES TOTAIS, NO RÚMEN E NO INTESTINO*.

\begin{tabular}{|c|c|c|c|c|}
\hline & \multicolumn{3}{|c|}{ Tratamentos } & \multirow[b]{2}{*}{ CV (\%) } \\
\hline & $\mathrm{RU}$ & RA & $\mathrm{RL}$ & \\
\hline & & Quantidades de N (g/dia) & & \\
\hline Ingerido & 95,51 & 90,56 & 95,86 & 16,66 \\
\hline Abomaso & 74,95 & 85,77 & 86,04 & 19,09 \\
\hline Fezes & $37,39 a$ & $\begin{array}{l}47,88 \mathrm{ab} \\
\text { Quantidades de N (g/kgPV } \\
0,75)\end{array}$ & $50,42 \mathrm{~b}$ & 22,02 \\
\hline Ingerido & 1,88 & 1,84 & 1,88 & 11,98 \\
\hline Fezes & $0,74 \mathrm{a}$ & $\begin{array}{c}0,96 \mathrm{~b} \\
\text { Digestibilidade aparente (\%) }\end{array}$ & $0,98 \mathrm{~b}$ & 17,09 \\
\hline Total & $60,92 \mathrm{a}$ & $46,66 \mathrm{~b}$ & $46,37 \mathrm{~b}$ & 16,62 \\
\hline Rúmen $^{1}$ & $\begin{array}{l}15,20 \\
5361\end{array}$ & $\begin{array}{l}-8,29 \\
4999\end{array}$ & $\begin{array}{l}-0,54 \\
4464\end{array}$ & $\begin{array}{l}995,47 \\
16,40\end{array}$ \\
\hline
\end{tabular}

RU: ração com uréia; RA: ração com farelo de algodão; RL: ração com levedura;

${ }^{1} \mathrm{em}$ relação ao que chega no abomaso; ${ }^{2} \mathrm{em}$ relação ao que é eliminado nas fezes;

Médias nas linhas seguidas de letras diferentes diferem ao nível de $5 \%$ de probabilidade;

${ }^{*}$ Digestibilidade aparente no intestino (ID = intestino delgado $+I G=$ intestino grosso). 
$\mathrm{O} N$ excretado pelas fezes foi superior $(\mathrm{P}<0,05)$ para as dietas contendo farelo de algodão (RA) e levedura $(R L)$.

Quando a quantidade de $\mathrm{N}$ excretado nas fezes foi expressa em g/dia a dieta RA apresentou média (47,88 g N/dia) estatisticamente igual $(P>0,05)$ a dieta $R U$ (37,39 g N/dia) e RL (50,42 g N/dia), porém, RU e RL foram consideradas estatisticamente diferentes $(\mathrm{P}<$ $0,05)$. Quando expressa em g/kgPV ${ }^{0,75}$ observou-se que as quantidades de $\mathrm{N}$ eliminadas pelos animais nas dietas
RA e $R L$ foram superiores $(P<0,05)$ a dieta cuja fonte nitrogenada foi a uréia $(R U)$.

A digestibilidade aparente do $\mathrm{N}$ foi superior $(\mathrm{P}<0,05)$ na dieta $\mathrm{RU}(53,61 \%)$ em relação às dietas $R A$ e $R L$ $(46,66$ e 46,37 \%, respectivamente).

Na TABELA 5, são apresentadas as quantidades de compostos nitrogenados amoniacais $\left(\mathrm{N}-\mathrm{NH}_{3}\right)$ e não amoniacais (NNA) presentes no abomaso e nas fezes, NNA absorvido no intestino e digestão aparente do NNA no intestino.

TABELA 5 - QUANTIDADE DE COMPOSTOS NITROGENADOS AMONIACAIS (N-NH $)_{3}$ E NÃO AMONIACAIS (NNA) PRESENTES NO ABOMASO E NAS FEZES; NNA ABSORVIDO NO INTESTINO E DIGESTIBILIDADE APARENTE DO NNA NO INTESTINO DE BOVINOS.

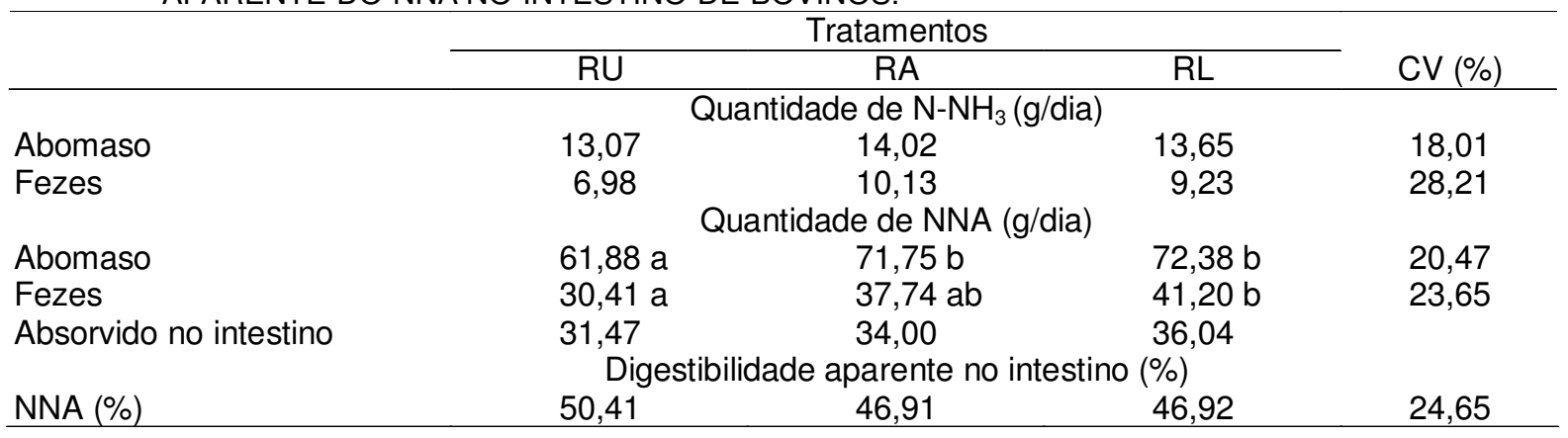

$\mathrm{RU}$ : ração com uréia; RA: ração com farelo de algodão; $R L$ : ração com levedura;

Médias nas linhas seguidas de letras diferentes diferem ao nível de $5 \%$ de probabilidade;

Digestibilidade aparente no intestino (ID = intestino delgado + IG = intestino grosso).

Para os parâmetros avaliados observou-se que a quantidade de compostos amoniacais $\left(\mathrm{N}-\mathrm{NH}_{3}\right)$ presente no abomaso e nas fezes não diferiu $(P>0,05)$ quando se variou a fonte nitrogenada das dietas. Porém, para os compostos nitrogenados amoniacais, representados pelos aminoácidos presentes na proteína, algumas diferenças foram observadas.

Apesar de não ocorrerem diferenças $(P>0,05)$ para a quantidade de compostos não amoniacais absorvidos no intestino ( $\mathrm{g} / \mathrm{dia})$, houve diferenças estatísticas $(\mathrm{P}<$ $0,05)$ entre as quantidades de NNA presentes no abomaso e eliminadas pelas fezes.

As quantidades de NNA presentes no abomaso e excretadas nas fezes foram inferiores $(P<0,05)$ para a dieta contendo uréia $(61,88$ e 30,41 g/dia, respectivamente), em relação às demais dietas.

As dietas RA e RL, apesar de apresentarem as maiores quantidades de NNA presentes no abomaso (71,75 e 72,38 g/dia respectivamente) em relação à dieta RU $(P<0,05)$, também foram as que apresentaram as maiores quantidades eliminadas nas fezes (37,74 e 41,20 $\mathrm{g} /$ dia, respectivamente); isto contribuiu para que a quantidade de NNA absorvida no intestino (g/dia) não apresentasse diferenças significativas entre as dietas $(P>0,05)$.

Também não foram observadas diferenças estatísticas $(P>0,05)$ para a digestibilidade aparente no intestino dos compostos NNA, estando a digestibilidade média destes compostos, para as três dietas avaliadas, na média de 48,08\%. Os valores de digestibilidade aparente dos compostos NNA foram muito próximos para as dietas RA e RL $(46,91$ e 46,92 $\%$, respectivamente).

As quantidades de NNA presentes no abomaso ( $\mathrm{g} /$ dia) foram próximas aos valores obtidos por McALLAN e SMITH (1984), apesar das fontes nitrogenadas utilizadas por estes autores serem muito diferentes às deste experimento.

O fluxo de NNA no abomaso obtido nas três dietas avaliadas foram superiores ao obtido por VALADARES FILHO et al. (1990) de 47,13 g/dia, apesar da digestibilidade aparente reportada pelos autores de 77 $\%$ ter sido, em média, 36,4\% superior às obtidas neste estudo, porém inferiores aos apresentados por VALADARES et al. (1997), quando estes utilizaram dietas com mais de $9,5 \%$ de proteína.

\section{Conclusões}

Nas condições do presente trabalho conclui-se que a fonte nitrogenada interferiu sobre a digestibilidade aparente do nitrogênio das dietas.

Houve maior quantidade de nitrogênio não amoniacal presente no abomaso para as dietas, cuja fonte proteica foi constituída de farelo de algodão e levedura, porém a quantidade absorvida no intestino não foi alterada, demonstrando que a capacidade de absorção foi limitada na composição do presente estudo. 
Digestibilidade da fração nitrogenada em bovinos alimentados com rações contendo diferentes fontes de nitrogênio

\section{Referências}

ASSOCIATION OF OFFICIAL ANALYTICAL CHEMISTS. Official methods of analysis of the association of official analytical chemists. 11.ed. Washington, 1970. 1015 p.

CLARK, J.H., KLUSMEYER, T.H. E CAMERON, M.R. Microbial protein synthesis and flows of nitrogen fractions to the duodenum of dairy cows Journal of Dairy Science, Savoy, v.75, n.8, p.2304-23, 1992.

COOMER, J.C., AMOS, H.E., FROETSCHEL, M.A., RAGLAND, K.K., WILLIAMS, C.C. Effects of supplemental protein source on ruminal fermentation, protein degradation, and amino acid absorption in steers and growth and feed efficiency in steers and heifers. Journal of Animal Science, Savoy, v.71, n.11, p.3078-86, 1993.

KING, K .J.; HUBER, J. T.; SADIK, M.; BERGEN, W. G.; GRANT, A. L.; KING, V. L. Influence of dietary protein sources on the amino acid profiles available for digestion and metabolism in lactating cows. Journal of Dairy Science, Savoy, v.73, n.2, p.320816, 1990.
McALLAN, A. B., SMITH R. H. The efficiency of microbial protein synthesis in the rumen and the degradability of feed nitrogen between the mouth and abomasum in steers given different diets. British Journal of Nutrition, Cambrigde, v.51, n.1, p.77-83, 1984.

NATIONAL RESEARCH COUNCIL - NRC. Nutrient requeriments of dairy cattle. 6 .ed. Washington: National Academy Press, 1989. 157p.

STEEL, R.G.D., TORRIE, J. H. Principles and procedures of statistics: a biometrical aprroach. 2 ed. Nova York: McGraw-Hill, 1981. 633p.

VALADARES FILHO, S.C., COELHO DA SILVA, J.F., SANT'ANNA, R. Eficiência de síntese microbiana em novilhos holandeses, nelores e búfalos mestiços, obtida por diferentes métodos. Revista da Sociedade Brasileira de Zootecnia, Viçosa, v.19, n.5, p.424-30, 1990.

VALADARES R. F. D.; GONÇALVES, L. C.; RODRIGUEZ, N. M. et al. Níveis de proteína em dietas de bovinos. 3. PH, amônia e eficiência microbiana. Revista da Sociedade Brasileira de Zootecnia, Viçosa, v.26, n.6, p.1264-9, 1997. WILLIAMS, C.H., DAVID, D.J., IISMAA, O. The determination of chromic oxide in faeces samples by atomic absorption spectrophotometry. Journal of Agriculture Science, Loughborough, v.59, n.3, p.381-92, 1962.

Recebido para publicação: $\quad$ 16/11/2005

Aprovado: 12/02/2006 